\title{
Evaluating organochlorine pesticide residues in the aquatic environment of the Lake Naivasha River basin using passive sampling techniques
}

\author{
Yasser Abbasi • Chris M. Mannaerts
}

Received: 3 November 2017 / Accepted: 2 May 2018 / Published online: 18 May 2018

(C) The Author(s) 2018

\begin{abstract}
Passive sampling techniques can improve the discovery of low concentrations by continuous collecting the contaminants, which usually go undetected with classic and once-off time-point grab sampling. The aim of this study was to evaluate organochlorine pesticide (OCP) residues in the aquatic environment of the Lake Naivasha river basin (Kenya) using passive sampling techniques. Silicone rubber sheet and Speedisk samplers were used to detect residues of $\alpha$ $\mathrm{HCH}, \beta-\mathrm{HCH}, \gamma-\mathrm{HCH}, \delta-\mathrm{HCH}$, heptachlor, aldrin, heptachlor epoxide, pp-DDE, endrin, dieldrin, $\alpha$-endosulfan, $\beta$-endosulfan, pp-DDD, endrin aldehyde, ppDDT, endosulfan sulfate, and methoxychlor in the Malewa River and Lake Naivasha. After solvent extraction from the sampling media, the residues were analyzed using gas chromatography electron capture detection (GC-ECD) for the OCPs and gas chromatographymass spectrometry (GC-MS) for the PCB reference compounds. Measuring the OCP residues using the silicone rubber samplers revealed the highest concentration of residues ( $\sum$ OCPs of $\left.81( \pm 18.9 \mathrm{SD}) \mu \mathrm{g} / \mathrm{L}\right)$ to be at the Lake site, being the ultimate accumulation
\end{abstract}

Y. Abbasi $(\bowtie) \cdot$ C. M. Mannaerts

Department of Water Resources (WRS), Faculty of Geo-information Sciences and Earth Observation (ITC), University of Twente (UT), P.O. Box 217, 7500AE, Enschede, The Netherlands

e-mail: y.abbasi@utwente.nl

C. M. Mannaerts

e-mail: c.m.m.mannaerts@utwente.nl environment for surficial hydrological, chemical, and sediment transport through the river basin. The total OCP residue sums changed to $71.5( \pm 11.3 \mathrm{SD}) \mu \mathrm{g} / \mathrm{L}$ for the Middle Malewa and $59( \pm 12.5 \mathrm{SD}) \mu \mathrm{g} / \mathrm{L}$ for the Upper Malewa River sampling sites. The concentration sums of OCPs detected using the Speedisk samplers at the Upper Malewa, Middle Malewa, and the Lake Naivasha sites were 28.2 ( $\pm 4.2 \mathrm{SD}), 31.3$ ( $\pm 1.8 \mathrm{SD})$, and $34.2( \pm 6.4 \mathrm{SD}) \mu \mathrm{g} / \mathrm{L}$, respectively. An evaluation of the different pesticide compound variations identified at the three sites revealed that endosulfan sulfate, $\alpha-\mathrm{HCH}$, methoxychlor, and endrin aldehyde residues were still found at all sampling sites. However, the statistical analysis of one-way ANOVA for testing the differences of $\sum$ OCPs between the sampling sites for both the silicone rubber sheet and Speedisk samplers showed that there was no significant difference from the Upper Malewa to the Lake site $(P<0.05)$. Finally, the finding of this study indicated that continued monitoring of pesticides residues in the catchment remains highly recommended.

Keywords Pesticide residues · Passive sampling · Silicone rubber sheet $\cdot$ Speedisk $\cdot$ Lake Naivasha

\section{Introduction}

The first application of organochlorine pesticides such as DDT and dieldrin dates back to 1956 and 1961, respectively, but due to the long half-life and their bioaccumulation in animal body, they were banned 
globally in 1976 (Keating 1983), except for regulated use of DDT for the control of malaria. After application of the chemicals, their residues can reach non-targets such as plants, soil, water, and sediment, by which these environmental compartments could be contaminated. Kaoga et al. (2013) explained that over 95\% of applied insecticides and herbicides end up in non-target areas. This could potentially endanger the environment and also contribute to public health problems (Mutuku et al. 2014). Although most of the pesticides have a short half-life and are easily degradable, there are still persistent pesticides such as first-generation organochlorine pesticides (OCPs), which have long time halflife and are persistent in environment. Consequently, they can be washed off to water bodies and cause considerable environmental risk (Gitahi et al. 2002). Lakes and reservoirs are typical accumulation sites for runoff, sediment, and chemicals in catchments, and therefore, these aquatic environments are at risk of being contaminated. Bearing in mind that due to the threat of pesticides, residues pose to aquatic life and ecosystems, careful evaluation is needed.

Aquatic monitoring programs are usually based on grab samples collected within a short time span. Grab sampling can only provide a snapshot of pollution levels (Hernando et al. 2007; Vrana et al. 2005) and also is associated with logistical and practical difficulties including transportation, filtration, extraction, and storage. Moreover, grab sampling as a way of monitoring pesticide pollution in aquatic environments cannot encompass all of the changes in pollutant concentrations (Ahrens et al. 2015). In other words, determining the dynamic status of pollution accurately during low and high flows is not entirely feasible with grab sampling. Consequently, the outcomes do not directly relate to the average load of pollutants (Jordan et al. 2013). In spite of these facts, grab sampling is useful for finding information quickly. However, extending measurements to cover fluctuations in flow and pollutant concentrations requires increasing the sampling frequency and sample numbers, which is expensive and time consuming while the results remain uncertain (Rozemeijer et al. 2010).

Due to the challenges related to grab sampling, the passive sampling technique is considered as a promising alternative method for measuring pollutants in aquatic environments. This method allows the accumulation of contaminants in the samplers, making it possible to determine very low concentrations of contaminants. Passive sampling provides means for continuous water quality monitoring from short term to long term (a week to some months) and allows determining time-weighted average (TWA) of contaminant concentrations (Ahrens et al. 2015). The chemical potential discrepancy between passive sampler media and the dissolved pollutants in the aquatic phase causes a partitioning of contaminants between water and the sampler (Allan et al. 2009). Moreover, in comparison with organisms, which undergo biotransformation and changing physiological conditions, the uptake of pollutants using passive samplers is more feasible (Smedes and Booij 2012). These features of passive sampling facilitate chemical examination of surface and other water bodies and provide an alternative approach to biomonitoring (Fox et al. 2010; Meyn et al. 2007; Munoz et al. 2010; Wille et al. 2011).

There are various kinds of non-polar passive samplers, which have been used for evaluating organic contaminants in aquatic environments (Brockmeyer et al. 2015). Passive samplers trap the pollutants in a kinetic or equilibrium diffusion, in which the whole process including selective analyte, isolation, and preconcentration occurs simultaneously (Vrana et al. 2005). The mass transfer of an analyte - an organic or inorganic compound-proceeds until the equilibrium phase occurs or the sampling is finished (Górecki and Namieśnik 2002). Silicone rubber (SR) sheets and Speedisk samplers were selected in this study for the determination of organochlorine pesticides because silicone rubber samplers for more hydrophobic compounds and Speedisk samplers for more hydrophilic compounds are ideal samplers that have some advantages such as simple construction, robust for installing in the rivers or the Lake, cheap, and commonly available (Smedes et al. 2010).

The Lake Naivasha catchment is a major agricultural areas in Kenya, and because of dense agricultural activity and population, there is a high demand for pesticides. Although there was a decline in organochlorine pesticide imports into the country, there is still risk of these pesticides' application in agricultural areas. Therefore, a monitoring plan for pesticide residue pollution in aquatic environments is necessary to evaluate their potential risk on ecosystems and humans in general. The aim of this research was to gain understanding in the organochlorine pesticide residue pollution and their spatial variation in the Lake Naivasha catchment using passive sampling techniques. 


\section{Materials and methods}

Study area

Lake Naivasha catchment is located in the eastern part of the Rift Valley region in Kenya with an area of about $3400 \mathrm{~km}^{2}$. The eastern rift has a tropical climate with two dry and two rainy seasons. The upper and middle parts of the catchment are mostly subjected to smallholder mixed farming for producing various crops. Moreover, there are various local dwellings in villages and towns all around the catchment that can influence the rivers and the Lake water quality located in the lower catchment. Input from upstream into the Lake includes water from the Malewa, Karati, and Gilgil Rivers plus surface runoff that drains from the catchment and reaches the Lake. But as the Malewa River accounts for approximately $80 \%$ of the inflow into Lake Naivasha, the samplers were installed in the Upper Malewa, Middle Malewa River, and the Lake (Fig. 1).
Sampler preparation and installation

Large AlteSil SR sheets were cut into pieces with $55 \times 90 \times 0.5$-mm dimensions and about $100 \mathrm{~cm}^{2}-$ both sides - surface area. The SR samplers were precleaned in Soxhlet apparatus with ethyl acetate for at least $100 \mathrm{~h}$ to remove all chains of oligomers. Then, they were air dried and spiked with performance reference compounds (PRCs). Based on Smedes and Booij (2012), the SR samplers need to be spiked with at least six PRCs that have a sampler-water partition coefficient $(\operatorname{logKpw})$ between 3.5 and 5.5 as well as a PRC that is rarely depleted $(\operatorname{logKpw}>6)$ and a completely depleted PRC $(\operatorname{logKpw}<3.3)$ for modeling water sampling rate and the concentration of the pollutants. Therefore, the applied PRCs in the SR samplers were BIP-D10, PCB001, PCB002, PCB003, PCB010, PCB014, РCB030, PCB050, PCB021, PCB104, PCB055, PCB078, PCB145, and PCB204. Then, the prepared SR samplers were

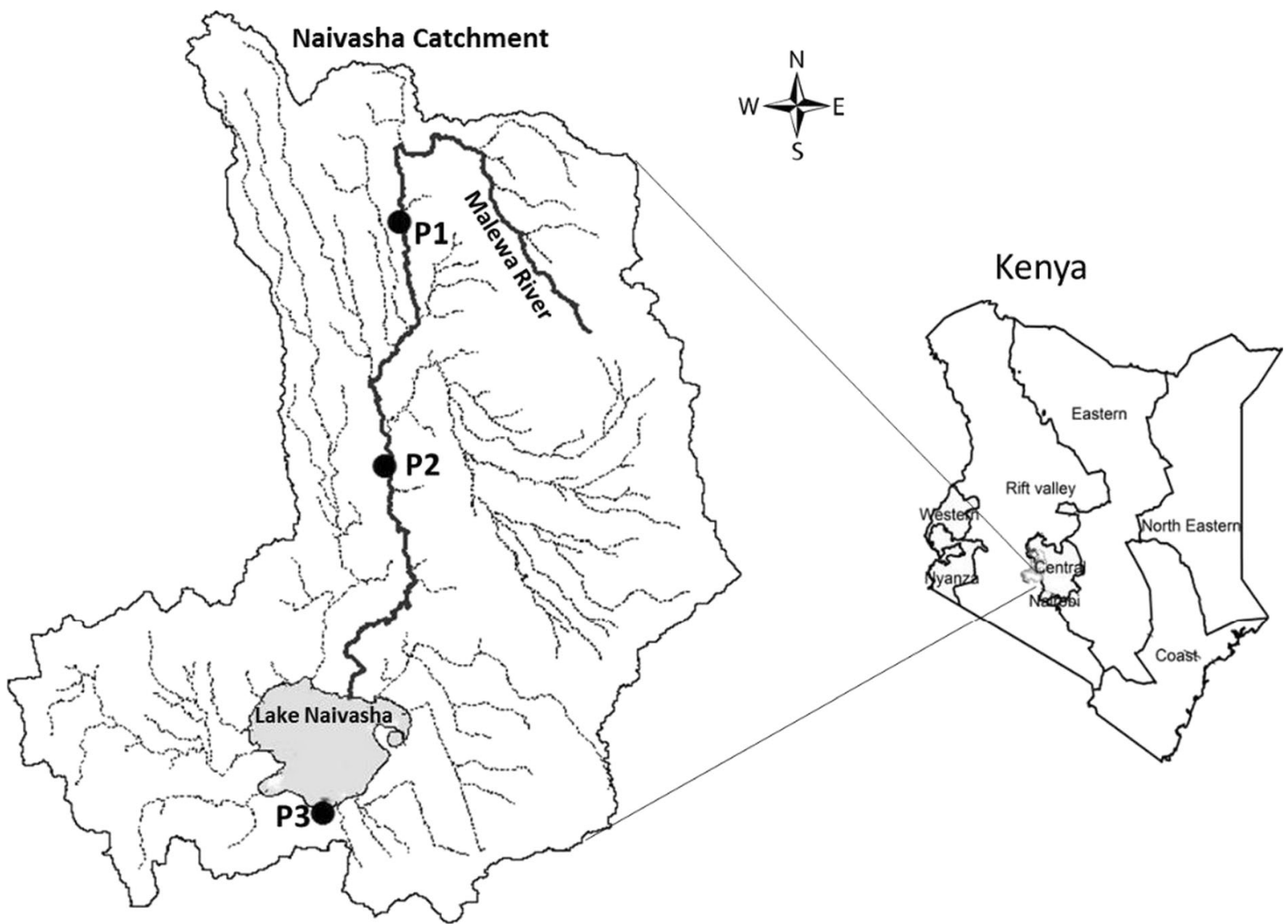

Fig. 1 The study area and locations of passive samplers (P1, P2, and P3 are Upper Malewa, Middle Malewa, and the Lake sites, respectively) 
kept in air-tightened amber glass bottles in the freezer $\left(-20^{\circ} \mathrm{C}\right)$ until installation.

Speedisk extraction samplers, $\mathrm{H}_{2} \mathrm{O}$-philic DVB low capacity $(0.6 \mathrm{~g})$ produced by Avantor, were also used for more hydrophilic substances. The Speedisks were conditioned by eluting them slowly with $15 \mathrm{~mL}$ dichloromethane (HPLC grade, 99.9\%), $10 \mathrm{~mL}$ acetone (HPLC grade, $99.5 \%$ ), and $20 \mathrm{~mL}$ distilled water, sequentially. They were then stored in a bottle of purified water and stored at $+4{ }^{\circ} \mathrm{C}$ until deployment.

At the sampling sites, including two sites in the Malewa River and one site in the Lake Naivasha as represented in Fig. 1, three sets of silicone rubber sheets and three sets of Speedisk passive samplers were installed for monitoring the concentrations of $\alpha-\mathrm{HCH}, \beta-\mathrm{HCH}, \gamma-$ $\mathrm{HCH}, \delta-\mathrm{HCH}$, heptachlor, aldrin, heptachlor epoxide, $\alpha$ endosulfan, pp-DDE, endrin, dieldrin, $\beta$-endosulfan, ppDDD, endrin aldehyde, pp-DDT, endosulfan sulfate, and methoxychlor in the Malewa River and the Lake Naivasha. Both the Speedisk and silicone rubber sheet samplers were mounted on metal wire mesh (Fig. 2) and immediately deployed in water. Additionally, one sampler was exposed to the air while installing the samplers, as reference sampler. Passive samplers were deployed in the water for 1 month from 20 June to 20 July 2016, during the long rainy season when most of the agricultural activity and use of pesticides occur. After 1 month, the samples were collected from the sampling sites. As they were covered by some fouling or algae, they were cleaned using a pre-treated scourer (washed and rinsed with methanol and water) and the water of the same sampling site. Then, the samplers were kept in a cool box (about $5{ }^{\circ} \mathrm{C}$ ) during transfer and at $-20{ }^{\circ} \mathrm{C}$ in the laboratory till treatment and analysis (Monteyne et al. 2013; Smedes and Booij 2012).

\section{Extraction and analysis}

Various solvents such as acetonitrile, hexane, acetone, dichloromethane, and methanol were used to extract the non-polar contaminants from the samplers. The solvents were all of HPLC grade (>99\% purity) in order to extract the studied OCPs. All of the procedures for both the exposed passive samplers and the blanks (control samplers) such as sampler extraction by Soxhlet apparatus, cleanup, concentration, and instrumental analysis were done according to the guidelines by Smedes and Booij (2012) and standard laboratory methods. After solvent extraction from the sampling media, the residues were determined using a gas chromatograph (Agilent 6890N) in combination with an electron capture detector (Agilent $\mu \mathrm{ECD}$ ) and an auto sampler (Agilent 7683 Series injector) for the OCPs (in Department of Chemistry at University of Nairobi, Kenya), and a gas chromatography (Agilent 7890A) coupled with a mass spectrometer (Agilent 7000 Series Triple Quadrupole MS detector) that had a possibility to measure with an MSMS method for the PRCs in Deltares (TNO laboratory, Netherlands). The temperature program of $\mathrm{GC}-\mu \mathrm{ECD}$ was set as initially $90{ }^{\circ} \mathrm{C}$ (3 min), then 90 to $200{ }^{\circ} \mathrm{C}$ (at $30{ }^{\circ} \mathrm{C} / \mathrm{min}$ and hold
Fig. 2 Mounting Speedisk (SD; left) and silicone rubber sheet (SR; right) passive samplers for deployment

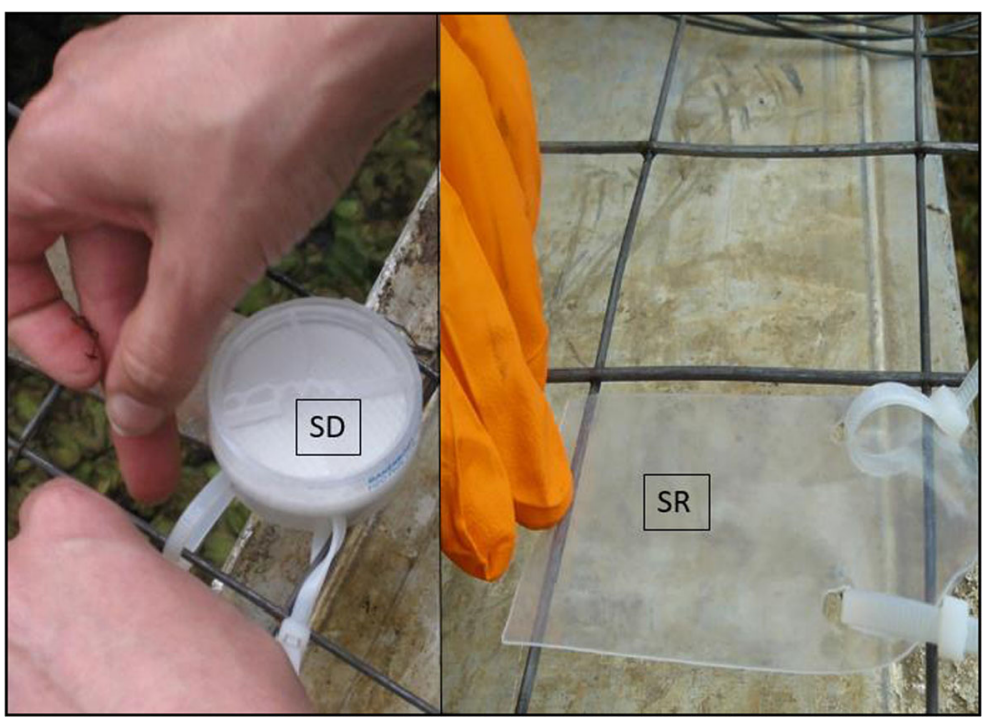


time of $15 \mathrm{~min}$ ), and 200 to $275^{\circ} \mathrm{C}$ (at $30{ }^{\circ} \mathrm{C} / \mathrm{min}$ and hold time of $5 \mathrm{~min}$ ). The carrier gas was helium and nitrogen was used as make-up gas with a continuous stream of $2 \mathrm{~mL} / \mathrm{min}$. The injection mode was pulsedsplitless with a volume of $1 \mu \mathrm{L}$. The column was a DB-5 (Agilent, USA) with length of $30 \mathrm{~m}$, internal diameter of $0.32 \mathrm{~mm}$, and film thickness of $0.25 \mu \mathrm{m}$. The calibration of the machine was done using the standards of organochlorine pesticides (purity of more than 99\%) in 10 concentration levels of 1, 5, 10, 50, 100, 200, 400, 600, 800 , and $1000 \mu \mathrm{g} / \mathrm{L}$. Finally, the quality control of the results was done by triplication for all the samples, and determination of recovery rates from blank treatments. The column of the GC-MS was also DB-5 (length $30 \mathrm{~m}$, ID $0.25 \mathrm{~mm}$, film $0.25 \mu \mathrm{m}$ ). The temperature program was set as initially $70^{\circ} \mathrm{C}$ for $1 \mathrm{~min}$, then ramp 1 increase $20^{\circ} \mathrm{C} / \mathrm{min}$ to $120 \mathrm{~min}$, hold time $0 \mathrm{~min}$; ramp 2 increase $6{ }^{\circ} \mathrm{C} / \mathrm{min}$ to $250^{\circ} \mathrm{C}$, hold time $0 \mathrm{~min}$; and ramp $317.5^{\circ} \mathrm{C} /$ min to $300{ }^{\circ} \mathrm{C}$, hold time $2.48 \mathrm{~min}$. The low detection limit was also $1 \mu \mathrm{g} / \mathrm{L}$ for all the PRCs.

\section{Calculations}

The amounts of PRC fraction $\left(f_{\exp }\right)$ indicates sampling rate and was estimated as

$f_{\exp }=\frac{N_{t}}{N_{0}}$

where $N_{t}$ and $N_{0}$ are the PRC amounts (ng) in the exposed and the reference samplers, respectively. Booij and Smedes (2010) showed that $f$ is a continuous function of Kpw and the sampling rate $\left(R_{S}\right)$ :

$$
f_{c a l}=e^{\frac{-R_{s} t}{K_{p w} m}}
$$

where $\mathrm{Kpw}$ is the sampler-water partition coefficient $(\mathrm{L} / \mathrm{kg}), R_{s}$ is the sampling rate (L/day), $m$ is the sampler weight $(\mathrm{kg})$, and $t$ is the exposure time (days). Rusina et al. (2010) demonstrated that sampling rate was a function of the hydrodynamic situation and the sampler surface area as well as the PRC molar mass (M). Therefore, their proposed Eq. (3) was used to demonstrate the relationship between these factors:

$R_{s}=\frac{F A}{M^{0.47}}$
The sampling rate was estimated by combining Eqs. (2) and (3) and fitting the retained fraction and $\mathrm{KpwM}^{0.47}$ using a solver package. The non-linear least squares (NLSs) method, which takes all of the PRCs into account, was applied for this aim (Booij and Smedes 2010).

Booij et al. (2007) showed that the amount of a target compound in the sampler can be presented as

$N_{t}=C_{w} \cdot K_{p w} m\left[1-\exp \left(\frac{-R_{s} t}{K_{p w} m}\right)\right]$

Therefore, by adjusting Eqs. (3) and (4), the concentration of compounds was determined as

$C_{w}=\frac{N_{t}}{K_{p w} m\left[1-\exp \left(-\frac{F A t}{M^{0.47} K_{p w} m}\right)\right]}$

Finally, the standard deviations (SDs) of the sampling rates as well as the pesticide concentration were calculated and included to the results. The statistical analysis of one-way ANOVA was also applied to explore the differences of total OCPs between the sampling sites at $95 \%$ confidence. This examination determined the spatial variation from the upper catchment to the Lake for the results of both kinds of passive samplers.

\section{Results and discussion}

Frequent measurements of different parameters at the sampling sites during sampler exposure time are presented in Table 1. It was found that the average acidity of water in the Malewa River and the Lake was between 7 and 7.8, and no remarkable difference was found. Moreover, the effect of water temperature on sampling rate has been studied by Booij et al. (2003), and they showed that sampling rate at $30^{\circ} \mathrm{C}$ was three times more than $20^{\circ} \mathrm{C}$. This issue demonstrates the relations between water temperature and up taking the contaminants. However, by calculating the sampling rates, the effect of different factors (e.g., oxygen saturation, salinity, conductivity, temperature, $\mathrm{pH}$ ) on the sampler performance is taken to account.

The results of analysis showed that after 30 days of passive sampler deployment, the average of minimum remaining PRCs on the silicone samplers was $4.7 \%$ 
Table 1 Physicochemical properties of water at the sampling sites

\begin{tabular}{|c|c|c|c|c|c|c|}
\hline Location/parameter & & $\mathrm{pH}$ & $T\left({ }^{\circ} \mathrm{C}\right)$ & $\mathrm{EC}(\mu \mathrm{S} / \mathrm{cm})$ & Sal. $(\% o)$ & Sat. $\mathrm{O}_{2}(\%)$ \\
\hline \multirow[t]{3}{*}{ The Lake } & Average & 7.8 & 20.1 & 352.2 & 0.11 & 87.1 \\
\hline & Minimum & 6.8 & 18.6 & 309.0 & 0.10 & 53.7 \\
\hline & Maximum & 8.6 & 21.0 & 366.0 & 0.12 & 104.8 \\
\hline \multirow[t]{3}{*}{ Middle Malewa } & Average & 7.4 & 16.3 & 147.6 & 0.05 & 103.6 \\
\hline & Minimum & 6.7 & 15.0 & 111.0 & 0.04 & 100.3 \\
\hline & Maximum & 8.6 & 18.0 & 170.0 & 0.06 & 106.4 \\
\hline \multirow[t]{3}{*}{ Upper Malewa } & Average & 7.7 & 16.3 & 150.4 & 0.05 & 103.2 \\
\hline & Minimum & 7.0 & 15.6 & 120.0 & 0.04 & 101.7 \\
\hline & Maximum & 8.9 & 17.2 & 174.2 & 0.06 & 105.0 \\
\hline
\end{tabular}

EC electrical conductivity, Sal. salinity, Sat. $\mathrm{O}_{2}$ oxygen saturation

( \pm 4.1 SD) for BCP-d10 and the maximum average was $97 \%$ ( \pm 7.4 SD) for PCB204. The amounts of remaining PRCs with a logKpw of less than 4.2, such as PCB001 and BIP-D10, occurred on less than $20 \%$ of the samplers. The PRCs of PCB014 and PCB104 with a $\operatorname{logKpw}$ of more than 5.1 showed a variation of $73 \%$ $( \pm 16.7 \mathrm{SD})$ to $102 \%( \pm 1.1 \mathrm{SD})$, which was in agreement with the results of the study by Monteyne et al. (2013). They indicated that the dissipation of more than $80 \%$ and less than $20 \%$ of the PRCs leads to difficulties in determining the initial and the final ratio of the PRCs on the samplers. Therefore, it could be concluded that the PRCs with a $\operatorname{logKpw}$ of 4.2 (PCB002) to 5.2 (PCB030) would be the most appropriate ones for calculating sampling rate. Moreover, as was concluded in other literature (Allan et al. 2009; Monteyne et al. 2013), the transition between linear and equilibrium phases occurred for the PRCs with $\operatorname{logKpw}$ between 4.2 and 5.2. Therefore, PCB010 and other compounds with this range of $\log \mathrm{Kpw}$ were still releasing and the sampling was continued.

The results of NLS model showed that there was a good fit between the measured and calculated PRC fractions (Fig. 3). Inclusion of a PRC with a low logKpw such as BIP-D10, which has a logKpw of 3.6, and PCB204, which has a high $\operatorname{logKpw}$ of 7.6, as well as other PRCs within this range led to a sigmoid trend among the retained fractions and $\log \left(\mathrm{Kpw} \cdot \mathrm{M}^{0.47}\right)$. With this approach, the results showed a minimum sampling rate occurring in the samplers that deployed in Lake Naivasha with $1.9( \pm 0.4 \mathrm{SD}) \mathrm{L} /$ day and a maximum rate at the Middle Malewa river site with $13.1( \pm 1.7 \mathrm{SD}) \mathrm{L} /$ day. The average sampling rate at the Upper Malewa river site was $6.2( \pm 0.7 \mathrm{SD}) \mathrm{L} /$ day, an intermediate result compared to other sites. Silicone sheets have been used mostly for monitoring the PAHs and PCBs in marine aquatic environments. However, comparing the results of this study with other literature showed that these results were comparable with the study by Harman et al. (2009), who reported sampling rates between 4.1 and $14.8 \mathrm{~L} /$ day for a duration of 6 weeks.

The data of sampling rates were used to determine the pesticide concentrations in the water $(\mathrm{Cw})$. This approach allowed the use of passive sampling technique to monitor non-polar compounds. Calculating the concentration of OCPs with SR samplers showed that the total amount of $\alpha-\mathrm{HCH}, \beta-\mathrm{HCH}, \gamma-\mathrm{HCH}, \delta-\mathrm{HCH}$, heptachlor, aldrin, isodrin, heptachlor epoxide, $\alpha$-endosulfan, pp-DDE, endrin, dieldrin, $\beta$-endosulfan, pp-DDD, endrin aldehyde, pp-DDT, endosulfan sulfate, and methoxychlor at the Lake site was the highest with a total amount of organochlorine pesticide residue ( $\sum$ OCPs) of $81( \pm 18.9$ SD) $\mu \mathrm{g} / \mathrm{L}$. This total amount was $71.5( \pm 11.3 \mathrm{SD})$ and $59( \pm 12.6 \mathrm{SD}) \mu \mathrm{g} / \mathrm{L}$ for the Middle Malewa and the Upper Malewa river sites, respectively. The reason of reporting the results as a summation of OCPs is that the individual concentrations of the OCPs were mostly low ranging from below detection limit to $56 \mu \mathrm{g} / \mathrm{L}$.

The variation in pesticides found at the three sampling sites using SR samplers was also investigated to evaluate possible differences in pesticide residue occurrence in different parts of the catchment (Fig. 4). Although there was an increasing trend from the Upper Malewa to the Lake, the results of one-way ANOVA for the means of the three sampling sites using SR samplers showed that there was not a significant spatial variations 


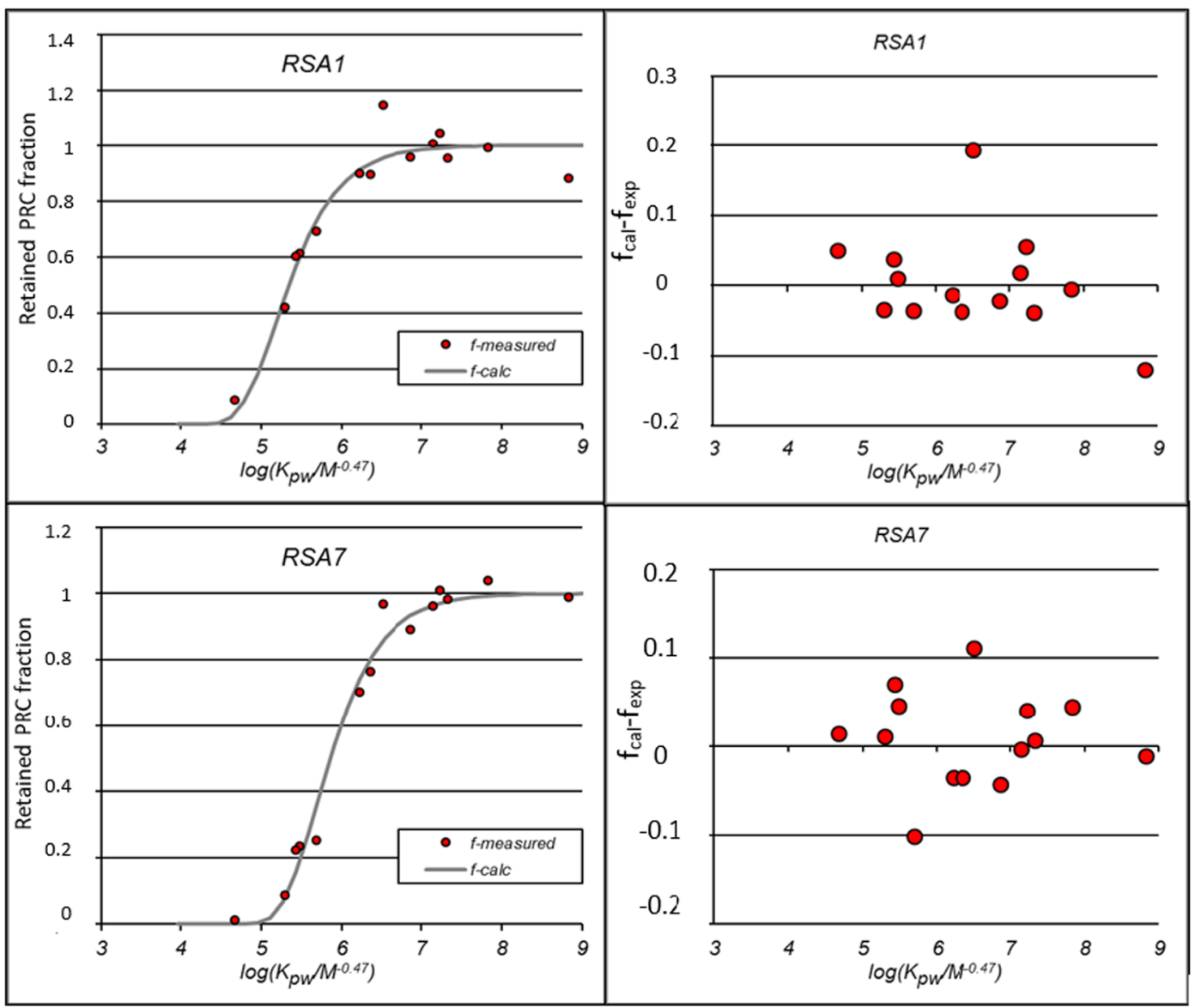

Fig. 3 Example diagram of $\operatorname{logKpw}$ versus retained PRC fractions (left) and difference of calculated and measured (calc.) $(r i g h t)$. The drawn line represents the best non-linear square for two example sites. RSA1 and RSA7 are example samples in the Lake and in Malewa River, respectively

respectively, that accounted, respectively, for 69,55 , and $58 \%$ of $\sum$ OCPs in these sites. The second major pesticide residue found on the SR samplers at all of the sites was $\alpha-\mathrm{HCH}$. The concentration of this pollutant varied from $19.3( \pm 6.7 \mathrm{SD}) \mu \mathrm{g} / \mathrm{L}$ at the Middle Malewa river site (27\% of the $\sum$ OCPs) to the amount of $11.3( \pm 4.8$ $\mathrm{SD}) \mu \mathrm{g} / \mathrm{L}$ at the Lake site. $\alpha-\mathrm{HCH}$ is an isomer of hexachlorocyclohexane $(\mathrm{HCH})$ that has different isomers, and the main ones are $\alpha-\mathrm{HCH}, \beta-\mathrm{HCH}, \gamma-\mathrm{HCH}$, and $\delta-\mathrm{HCH}$. All of these isomers are insecticides that are mostly used on fruit, vegetables, and animals. $\alpha-\mathrm{HCH}$ is by-product of lindane, but due to the persistence in environment and bioaccumulation, it has been classified as persistent organic pollutant (POP) by Stockholm Convention on Persistent Organic Pollutants in 2009 (ATSDR 2005). Methoxychlor was also found in the SR samplers at all sampling sites. It is an insecticide that 


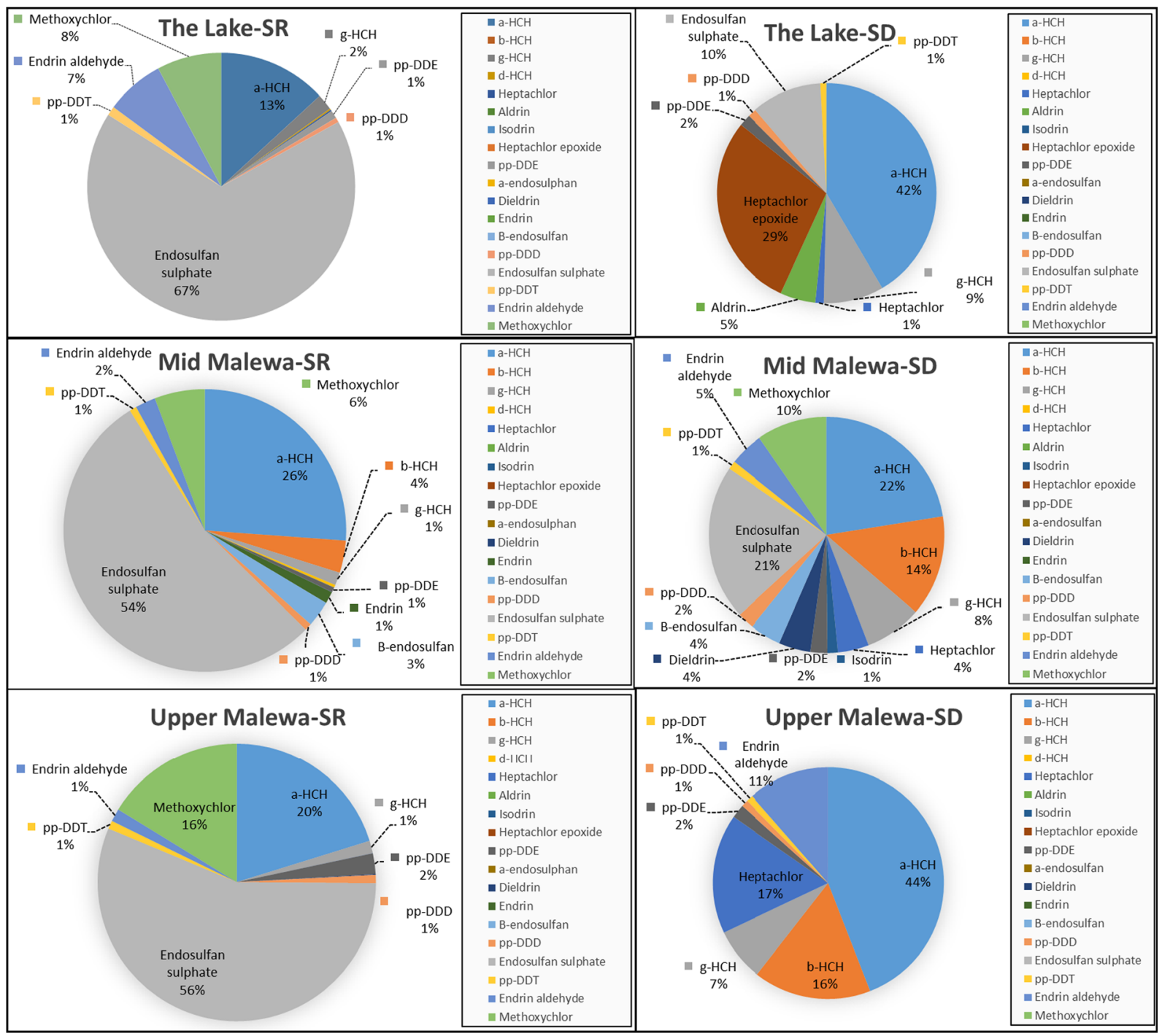

Fig. 4 Distribution of organochlorine pesticide residues on the silicone rubber (SR) and Speedisk (SD) passive sampling media at the three sampling sites (based on June-July 2016 sampling campaign data)

has a wide range of application for controlling the insects on crops, livestock, and homes. It dissolves in the water or evaporates into air very rarely, and once it reaches the ground, it sticks to the soil particles that can be transported to water bodies by runoff. The process of degradation in the environment is slow and may take several months (ATSDR 2002a). The ratio of other pesticides occurred in very low percentages. DDT, for instance, accounts for a very low percentage (1-2\%) of residue, and this finding is in agreement with previous studies, indicating that the use of this pesticide has significantly decreased (Gitahi et al. 2002). Although in very low concentration, endrin aldehyde was another pesticide that was found in the SR samplers at all of the sites. Comparing the results from the SR samplers at different sites showed that the Middle Malewa river site had most different kinds of applied pesticides. In addition to the mentioned pesticides that were found at the Lake and Upper Malewa river sites, $\beta-\mathrm{HCH}$, endrin, $\beta$ endosulfan, pp-DDD, and pp-DDE were found at the Middle Malewa river site. pp-DDD and pp-DDE, occurring with a concentration of less than $1 \mu \mathrm{g} / \mathrm{L}$ (almost $1 \%$ ratio of $\sum$ OCPs) at the Middle Malewa river site, are the metabolite of DDT, which may originate from pesticide application in the past still present in the environment. It is noticeable that DDT/(DDD + DDE) ratio is 
an indication of DDT application history that the amount of less than 1 means that there might not be current input of the parent DDT into the study area and vice versa (Gbeddy et al. 2012). The results showed that this ratio was less than 1 for the sampling sites.

Considering the sampling rates of Speedisk samplers and the total of pesticides taken up by these samplers, the maximum amount of pesticides was $\sum$ OCPs $=34.2$ $( \pm 6.5 \mathrm{SD}) \mu \mathrm{g} / \mathrm{L}$ that was found at the Lake Naivasha site. The amounts of $\sum$ OCPs from the Speedisk samplers at Middle Malewa and Upper Malewa sites were $31.3( \pm 1.8 \mathrm{SD})$ and $28.2( \pm 4.2 \mathrm{SD}) \mu \mathrm{g} / \mathrm{L}$, respectively. Based on the one-way ANOVA results of Speedisks for exploring the spatial variations of the OCPs at the sampling sites, these amounts were not significantly different $(P>0.05)$.

Evaluating pesticide variation in the studied area by Speedisk samplers also demonstrated that $\alpha-\mathrm{HCH}$ occurred at all of the sampling sites (Fig. 4). The Lake site, with a concentration of $16.1( \pm 5.1 \mathrm{SD}) \mu \mathrm{g} / \mathrm{L}$, which is equivalent to $47 \%$ of $\sum \mathrm{OCPs}$, revealed the highest measured amount. The concentration of this pesticide's residue was 13 ( $\pm 1.9 \mathrm{SD}) \mu \mathrm{g} / \mathrm{L}$ in the Upper Malewa river and decreased to the $5.9( \pm 1.8 \mathrm{SD}) \mu \mathrm{g} / \mathrm{L}$ in the Middle Malewa river(19\% of $\sum$ OCPs). Although the Middle Malewa and Upper Malewa river sites were situated in the same river, the sites were placed far apart to discover the effect of the surrounding agricultural areas of the sampling sites on the pollution situation of the Malewa River. The selected site location in the Lake Naivasha was also at the opposite side of the Lake to the Malewa river estuary, in order to minimize the effect of Malewa River on the Lake Naivasha sampling site. Therefore, the results of each of the sites can be said to be mostly related to the pollution in adjacent areas. Moreover, although the interview with the farmers about the pesticides use for controlling any kind of diseases in their products (e.g., cabbage, tomato, potato, maize) did not show any OCP application, the results of sampler analysis demonstrated the OCP residues in the sampling sites. Nearly all of the explored $\mathrm{HCH}$ isomers were found in the Middle and Upper Malewa Rivers. It is noticeable that some of the OCPs such as $\alpha-\mathrm{HCH}, \beta-$ $\mathrm{HCH}, \gamma-\mathrm{HCH}, \delta-\mathrm{HCH}, \mathrm{pp}-\mathrm{DDT}$, pp-DDE, and ppDDD that are metabolites of $\mathrm{HCH}$ and DDT can remain in the environment for an extremely long time by accumulating in different environmental compartments. For instance, when DDT is broken down by microorganisms or under environmental condition, DDE and DDD are produced which are similar to their parents. The residue of these chemicals that are not dissolved easily in water can stick to soil particles and remain in environment up to 15 years (ATSDR 2002b).

Passive samplers accumulate pesticide residues from the water during deployment; therefore, they may be more useful than grab sampling for finding OCPs. Moreover, as the behavior of the passive samplers for accumulating the contaminants mimics the bioaccumulation by organisms (e.g., uptake of pesticides by aquatic biota like fish), the outcomes of passive sampling studies are more comparable with biomonitoring ones (Smedes and Booij 2012). Therefore, the results of this study can be compared with the study by Gitahi et al. (2002) that explored pesticide contamination in water resources of Naivasha using fish samples. Their study about organochlorine pesticide pollution in various species of fish, water, and sediment samples in Lake Naivasha demonstrated different levels of lindane, dieldrin, $\beta$-endosulfan, and aldrin in the fat of fish. Their results showed a technical use of these pesticides in the studied area, which would agree with the findings of this study.

Based on the report of the Pest Control Products Board of Kenya PCPB (2008), import and use of many of the studied pesticides have been discontinued. However, different studies (Gitahi et al. 2002; Onyango et al. 2014) indicated application of these pesticides in the Lake basin. Lindane was a commonly used pesticide in Kenya. It was used as insecticide and for seed dressing. $\mathrm{HCH}$ and its isomers are the main pesticide residues found in the Speedisk samplers. These results seem to indicate the use of $\mathrm{HCH}$ and its isomers in the Lake Naivasha catchment. Endosulfan sulfate is an oxidation product of endosulfan, which has a high acute toxicity and can be potentially bioaccumulated. Because of the threats of endosulfan and its isomers ( $\alpha$-endosulfan, $\beta$ endosulfan, and endosulfan sulfate) to human health and the environment, there was a global ban on its application under the Stockholm Convention. Based on Camacho-Morales and Sánchez (2015), the estimated half-life time of these chemicals (endosulfan and endosulfan sulfate) can vary from 9 months to 6 years. However, endosulfan sulfate was found in the SR samplers at all of the sampling sites.

Comparing the pollution levels of pesticides in the water for different sampling sites with the drinking water standards criteria (WHO 2011) showed that the concentrations of all the studied pesticides were below 
Fig. 5 Comparison of measured pesticide residue concentrations at the three sites studied to WHO drinking water standards

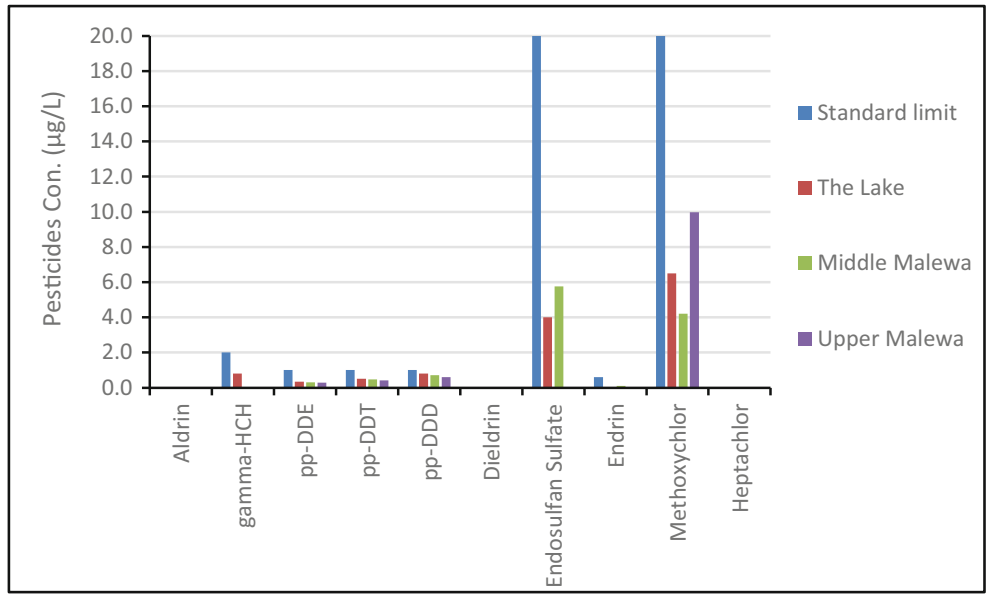

the WHO drinking water standard and limits (Fig. 5). Results of this study are in agreement with another recent pesticide residue study in the Lake basin by Onyango et al. (2015). They reported on 4,4-DDT, 2,4-DDE, 4,4-DDD, $\gamma-\mathrm{HCH}, \alpha-\mathrm{HCH}$, and aldrin contamination in the aquatic environment of the Lake Naivasha catchment and concluded that there was no potential effect of these pesticides on human health in drinking water. However, because of bioaccumulation of pesticides in aquatic organisms and the risk of entering the higher food web and chain, the concentration of pesticide residues, even in low concentrations, needs to be monitored continuously.

\section{Conclusions}

This study investigated organochlorine pesticide residues in surface water resources on Naivasha, Kenya using passive sampling techniques. Analysis of OCP concentrations showed that the total amounts at the Lake site was highest. This could be due to the fact that the Lake was the final accumulation site for runoff and suspended sediments from the basin. The $\sum \mathrm{OCPs}$ for the Middle Malewa and the Upper Malewa river sites represented the second and third levels, respectively. The results showed that endosulfan sulfate was the main pesticide residue found at all of the sampling locations. The results from the SR samplers showed that there was also contamination by $\alpha-\mathrm{HCH}$, endrin aldehyde, and methoxychlor at all of the sites. Finally, it was concluded that continuous monitoring of OCPs and other pesticides using passive sampling was a very useful technique that could contribute to environmental monitoring and pollution assessment of water resources in the studied area.

Acknowledgments This study commenced within the framework of the Integrated Water Resources Assessment Project - Naivasha or IWRAP project - and was completed in cooperation with the "Waterschap Noorderzijlvest" (the Netherlands) with support from the WWF (World Wildlife Fund for nature, Nairobi office) and the Water Resources Management Authority (WRMA) of Naivasha (Kenya). Passive samplers were prepared and dedicated by Deltares (the Netherlands), and chemical pesticide residue analysis was carried out in Department of Chemistry at University of Nairobi and in Deltares (TNO) laboratories (Utrecht, Netherlands). Authors would like to express thanks to Dr. Jasperien de Weert (Deltares Company, Utrecht, Netherlands), Prof. Onyari John Mmari, Dr. Madadi Vincent Odongo, and Mr. Enock Osoro (University of Nairobi) and the people in the WWF and WRMA, who all facilitated this study.

Open Access This article is distributed under the terms of the Creative Commons Attribution 4.0 International License (http:// creativecommons.org/licenses/by/4.0/), which permits unrestricted use, distribution, and reproduction in any medium, provided you give appropriate credit to the original author(s) and the source, provide a link to the Creative Commons license, and indicate if changes were made.

\section{References}

Ahrens, L., Daneshvar, A., Lau, A. E., \& Kreuger, J. (2015). Characterization of five passive sampling devices for monitoring of pesticides in water. Journal of Chromatography A, 1405, 1-11. https://doi.org/10.1016/j.chroma.2015.05.044.

Allan, I. J., Booij, K., Paschke, A., Vrana, B., Mills, G. A., \& Greenwood, R. (2009). Field performance of seven passive sampling devices for monitoring of hydrophobic substances. 
Environmental Science \& Technology, 43(14), 5383-5390. https://doi.org/10.1021/es900608w.

ATSDR, (Agency for Toxic Substances and Disease Registry). (2002a). Toxicological profile for Methoxychlor. U.S. Department of Health and Human Services, Public Health Service.

ATSDR, (Agency for Toxic Substances and Disease Registry). (2002b). Toxicological profile for DDT, DDE, and DDD. In U.S. Public Health Service: Department of Health and Human Services.

ATSDR, (Agency for Toxic Substances and Disease Registry). (2005). Toxicological profile for alpha-, beta-, gamma-, and Delta-Hexachlorocyclohexane. U.S. Department of Health and Human Services, Public Health Service.

Booij, K., \& Smedes, F. (2010). An improved method for estimating in situ sampling rates of nonpolar passive samplers. Environmental Science and Technology, 44(17), 67896794. https://doi.org/10.1021/es101321v.

Booij, K., Hofmans, H. E., Fischer, C. V., \& Van Weerlee, E. M. (2003). Temperature-dependent uptake rates of nonpolar organic compounds by semipermeable membrane devices and low-density polyethylene membranes. Environmental Science and Technology, 37(2), 361-366. https://doi. org/10.1021/es025739i.

Booij, K., Vrana, B., \& Huckins, J. N. (2007). Chapter 7 theory, modelling and calibration of passive samplers used in water monitoring. Comprehensive Analytical Chemistry, 48(6), 141-169. https://doi.org/10.1016/S0166-526X(06)48007-7.

Brockmeyer, B., Kraus, U. R., \& Theobald, N. (2015). Accelerated solvent extraction (ASE) for purification and extraction of silicone passive samplers used for the monitoring of organic pollutants. Environmental Science and Pollution Research., 22, 19887-19895. https://doi. org/10.1007/s11356-015-5192-1.

Fox, J. T., Adams, G., Sharum, M., \& Steelman, K. L. (2010). Passive sampling of bioavailable organic chemicals in Perry County, Missouri cave streams. Environmental Science and Technology, 44(23), 8835-8841. https://doi.org/10.1021 les1019367.

Gbeddy, G., Yeboah, P., Carboo, D., Doamekpor, L., Afful, S., Nartey, V., et al. (2012). Organochlorine pesticide residues in African catfish muscle, Nile tilapia muscle and gills from the middle Volta basin, Kpando Torkor, Ghana and their potential health risks to humans. Elixir Agriculture, 49(July), 9724-9730.

Gitahi, S. M., Harper, D. M., Muchiri, S. M., Tole, M. P., \& Ng'ang'a, R. N. (2002). Organochlorine and organophosphorus pesticide concentrations in water, sediment, and selected organisms in Lake Naivasha (Kenya). Hydrobiologia, 488, 123-128. https://doi.org/10.1023/A:1023386732731.

Górecki, T., \& Namieśnik, J. (2002). Passive sampling. TrAC Trends in Analytical Chemistry, 21(4), 276-291. https://doi. org/10.1016/S0165-9936(02)00407-7.

Harman, C., Thomas, K. V., Tollefsen, K. E., Meier, S., Bøyum, O., \& Grung, M. (2009). Monitoring the freely dissolved concentrations of polycyclic aromatic hydrocarbons (PAH) and alkylphenols (AP) around a Norwegian oil platform by holistic passive sampling. Marine Pollution Bulletin, 58(11), 16711679. https://doi.org/10.1016/j.marpolbul.2009.06.022.

Hernando, M. D., Lambropoulou, D., Konstantinou, I., Martinez Bueno, M. J., Gabrielides, D., Fernández-Alba, A. R., \&
Albanis, T. (2007). Passive sampling techniques for monitoring organic contaminants in aquaculture environment. In Proceedings of the 10th International Conference on Environmental Science and Technology (pp. B276-B283).

Jordan, P., Cassidy, R., Macintosh, K. a., \& Arnscheidt, J. (2013). Field and laboratory tests of flow-proportional passive samplers for determining average phosphorus and nitrogen concentration in rivers. Environmental Science \& Technology, 47(5), 2331-2338. https://doi.org/10.1021/es304108e.

Kaoga, J., Ouma, G., \& Abuom, P. (2013). Effect of farm pesticides on water quality in Lake Naivasha. Kneya. American Journal of Plant Physiology, 8, 105-113. https://doi. org/10.3923/ajpp.2013.105.113.

Keating, M. I. (1983). Tick control by chemical ixodicides in Kenya: A review 1912 to 1981. Tropical Animal Health and Production, 15(1), 1-6. https://doi.org/10.1007 /BF02250752.

Meyn, A., White, P. S., Buhk, C., \& Jentsch, A. (2007). Environmental drivers of large, infrequent wildfires: The emerging conceptual model. Progress in Physical Geography, 31(3), 287-312. https://doi.org/10.1177 $/ 0309133307079365$.

Monteyne, E., Roose, P., \& Janssen, C. R. (2013). Application of a silicone rubber passive sampling technique for monitoring PAHs and PCBs at three Belgian coastal harbours. Chemosphere, 91(3), 390-398. https://doi.org/10.1016/j. chemosphere.2012.11.074.

Munoz, I., Martinez Bueno, M. J., Aguera, A., \& Fernandez-Alba, A. R. (2010). Environmental and human health risk assessment of organic micro-pollutants occurring in a Spanish marine fish farm. Environmental Pollution, 158(5), 18091816. https://doi.org/10.1016/j.envpol.2009.11.006.

Mutuku, M., Njogu, P., \& Nyagah, G. (2014). Assessment of pesticide use and application practices in tomato based Agrosystems in Kaliluni sub location, Kathiani District, Kenya. JAGST, 16(2), 34-44.

Onyango, J., Kreuzinger, N., Yillia, P., \& Kitaka, N. (2014). Potential risks of pesticide application in Kenya : Case of Lake Naivasha catchment. In 7th International Young Water Professional Conference. Taipei, Chinese Taiwan.

Onyango, J., Kreuzinger, N., \& Kitaka, N. (2015). Pesticides residues contamination in Lake Naivasha catchment. Kenya: AV Akademikerverlag.

PCPB, (Pest Control Products Board). (2008). List of Pest control products provisionally registered by the Pest control products board for use in Kenya. Nairobi, Kenya.

Rozemeijer, J., Van Der Velde, Y., De Jonge, H., Van Geer, F., Broers, H. P., \& Bierkens, M. (2010). Application and evaluation of a new passive sampler for measuring average solute concentrations in a catchment scale water quality monitoring study. Environmental Science and Technology, 44(3), 13531359. https://doi.org/10.1021/es903068h.

Rusina, T. P., Smedes, F., Koblizkova, M., \& Klanova, J. (2010). Calibration of silicone rubber passive samplers: Experimental and modeled relations between sampling rate and compound properties. Environmental Science and Technology, 44(1), 362-367. https://doi.org/10.1021 les900938r.

Smedes, F., \& Booij, K. (2012). Guidelines for passive sampling of hydrophobic contaminants in water using silicone rubber 
samplers. ICES Techniques in Marine Environmental Sciences No. 52.

Smedes, F., Bakker, D., \& Weer, J. de. (2010). The use of passive sampling in WFD monitoring. Delft: Rijkswaterstaat Centre for Water Management, Deltares Project No. 1202337-004.

Vrana, B., Allan, I. J., Greenwood, R., Mills, G. a., Dominiak, E., Svensson, K., et al. (2005). Passive sampling techniques for monitoring pollutants in water. TrAC - Trends in Analytical Chemistry, 24(10), 845-868. https://doi.org/10.1016/j. trac.2005.06.006.

WHO. (2011). WHO guidelines for drinking-water quality. WHO chronicle, (Fourth Edition). https://doi.org/10.1016/S1462-
0758(00)00006-6, Guidelines for Drinking-Water Quality, 2nd edition, Addendum to Volume 1 - Recommendations, World Health Organisation, Geneva, 1998, 36 pages.

Wille, K., Claessens, M., Rappé, K., Monteyne, E., Janssen, C. R., De Brabander, H. F., \& Vanhaecke, L. (2011). Rapid quantification of pharmaceuticals and pesticides in passive samplers using ultra high performance liquid chromatography coupled to high resolution mass spectrometry. Journal of Chromatography A, 1218(51), 9162-9173. https://doi. org/10.1016/j.chroma.2011.10.039. 